\title{
Gender Based Violence and Violence against Women in Nigeria: A Sociological Analysis
}

\author{
Isma'il Husain Mshelia \\ Department of Sociology, University of Abuja, Abuja, Nigeria
}

\begin{abstract}
In this paper, the phenomenon of Gender Based Violence in Nigeria is examined in the light of Social Learning and Feminist theoretical perspectives. Using secondary data, different forms of violence were identified in the study and they include beating, rape, humiliation, verbal abuse, widowhood practices, early marriage, sexual harassment and female genital mutilation. Consequences of the acts as identified in the study include depression, suicide, murder, sexually transmitted diseases, and physical injuries. It is therefore recommended that government, individuals, civil society and non-governmental organizations should act accordingly towards eliminating the menace.
\end{abstract}

Keywords: Gender Based Violence, Violence against Women, Domestic Violence, Intimate Partner Violence.

\section{INTRODUCTION}

A ccording to Word Health Organization (WHO) report (2013 p.32), 35\% of women in the world have experienced either physical and/or sexual intimate partner violence or non-partner sexual violence. While Gender Based Violence affects women of all socio-economic backgrounds and educational levels, the women more likely than others to experience violence as identified by United Nations (UN) in the 1995 World Conference on Women in Beijing are women belonging to specific social categories. The social categories of women include the following, minority groups, refugee women, women migrants, women migrant workers, women in poverty living in rural or remote communities, destitute women, women in institutions or detention, female children, women with disabilities, elderly women, displaced women and repatriated women. While these categories are present across the globe, the regions of the world with the highest reported rates of sexual and physical violence towards women are the Middle East, Southeast Asia and Africa (WHO, 2013).As the comity of nations set and work towards achieving the 17 Sustainable Development Goals (SDG) by the year 2030, Gender Based Violence (GBV) continues to be a stumbling block to the achievement of equality (SDG goals 5 and 10), peace and justice (SDG goal 16). Feminist theorists attribute GBV to the structural inequality between men and women in the family as well as in the society. This is because, although men are more likely than women to be victims of violent crimes, women are far more likely to be victimized on the basis of their gender (Bachman, 1994, p. 15). Over the years, women have experienced significantly more GBV than men in virtually all societies of the world. As a result, Violence Against Women (VAW) emerged as a technical term used to refer to violent acts that are primarily or exclusively committed against women. The European Union (EU) identified four types of violence against women namely: Physical violence, Sexual violence, Economic violence and Psychological violence.

Acts or threats of any form of violence instil fear and insecurity in women and precipitates upen them psychological trauma, depression, injuries, sexually transmitted diseases and death. In its World Development Report (1993), the World Bank, assessed the health consequences of GBV and estimated that in industrialized countries, rape and domestic violence take away almost one in every five healthy years of the lives of women aged 15 to 44. Around the world, at least 1 woman in every 3 has been beaten, coerced into sex, or otherwise abused in her lifetime and most often the abuser is a member of her own family (UNFPA, p.11).

In various studies on sexual assaults and other forms of GBV in Africa, a significant percentage of female population ranging from 5\% to $15 \%$ reported being victimized (Daru et al., 2011, p.47). For instance, a study of 367 high school girls in Ethiopia showed that $11.4 \%$ of them had started having intercourse and that $33.3 \%$ of their sexual experience was rape. Another studystudyon the prevalence of rape in South Africa showed a figure of 2070 per 100,000 per year(Fitaw et al., 2005, p. 218; Jewkes \& Abraham, 2002, p.36). In a more recent study in South Africa, it is estimated that a woman is raped every 83 seconds and only 1 in 20 of these cases are ever reported to the police, while in the Midlands Province in Zimbabwe, $25 \%$ of women reported attempted or completed rape by an intimate partner (UNFPA, p.11). All these show that sexual abuse is a regular experience for many women in Africa with a significant percentage of them suffering it right from childhood. In addition to sexual assaults, UNFPA (p.11) further reported that more than 90 million African women and girls are victims of female circumcision or other forms of genital mutilation with more than 2 million girls undergoing the practice every year. The high social and economic costs of VAW has become a major threat to the social and economic development of countries the world over. As a result, respective governments and organizations actively work to combat the menace through variety of programs. There have been many international conferences and declarations on violence against women such as the International Conference on Population and Development (ICPD), the Beijing Platform for Action (BPA) and the Convention on the Elimination of All forms of Discrimination Against Women (CEDAW).The 
United Nations (UN) even designated November $25^{\text {th }}$ as the International Day for the elimination of VAW. In spite of the series of conferences and campaigns, the phenomenon still persists globally. in many countries of the world. The ultimate aim of the international actors is to see member states of the organizations take appropriate and effective preventive and punitive measures to eliminate all forms of VAW, but it is clear that despite progress recognized by legislations in virtually all the states, GBV still exist in the 21st Century (Osuna-Rodriguez et al., 2020 p.1). In fact, it remains one of the most prevalent and persistent issues facing women and girls globally (Perrin et al., 2019, p.2).

Nigeria is a signatory to the Universal Declaration of Human Rights (UDHR) and the Charter of African Human Rights Commission (AHRC) both of which aim to protect individuals against violence and other actions that interfere with fundamental freedom and human dignity. In addition, the 1999 constitution of the Federal Republic of Nigeria recognized and entrenched human rights as fundamental in chapter four. It is categorically stated in chapter two of the constitution that the Nigerian state's social order is founded on the ideals of freedom, equality and justice and that discrimination on the grounds of sex, religion and ethnic ties among others is prohibited. Yet, GBV is still common in the country as it is in other developing countries.

The objectives of this paper are to identify and examine the most prevalent forms of GBV in Nigeria; and to evaluate Nigerian legal framework on GBV. What are the forms of VAW commonly suffered by women in the country, their causes and consequences? How effective is the country's legal framework against GBV in the light of the country's social objectives built upon the ideals of freedom, equality and justice? Using relevant sociological theories, this paper offers an analysis that answers these questions. .

\section{THEORETICAL FRAMEWORK}

In this paper, the phenomenon of GBV is viewed in the light of Social Learning and Liberal Feminist perspectives. Postulated by Albert Bandura, the Social Learning theory states that people learn behavioural patterns from other people around them Bandura (1977, p.9). The theory assumes that the social environment causes people to behave in certain ways. In the views of Bandura (1986, p.29), modelling on parental behaviour may also be relevant to the understanding of violence against women. Thus, there is a general belief that a man who witnessed VAW in childhood is more likely to perpetrate it than a man who did not. The Social Learning theory suggest that early exposure to violence infuse in children cognitive beliefs condoning the use of interpersonal violence and thus increase the likelihood of them engaging in it (Eriksson \& Mazerolle, 2015). They also suggest that early learning of violence make children more likely to not only engage in it but to also approve of it later in their lives (Delaney, 2015; Gage, 2016). .
Many perpetrators of VAW in Nigeria today fit into these propositions. . As many women are abused by their intimate partners, most times the abusive behaviours occur in the presence of children. And this tends to have significant influence on their perception of women and how they should be treated in a relationship. The efficacy of the Social Learning theory of Bandura in explaining violence is obvious in Anderson and Kras's (2005) work on interpersonal and intergenerational violence. However, apart from learning through observation, there are other factors such as culture, religious practices and the low status of women which influence violence against them. To view the influence of these social factors, we have to utilize the Liberal Feminist theory. Until the advent of the feminist movement and a new scholarship of feminist model around VAW, the abuse of women by men was seen to be largely rooted in biological sex differences (Ahmed et al., 2004, p. 271).

The Feminist theory uses the conflict approach to examine the reinforcement of gender roles and inequalities, highlighting the role of patriarchy in maintaining the oppression of women (Thompson, 2016, para. 3).There are four broad types of Feminism - Radical, Marxist, Liberal, and Postmodern. Liberal Feminism, however, offers the most suitable framework for the understanding and explanation of violence against women in Nigeria. According to the Liberal Feminist theory, neither men nor women benefit from gender discrimination as both of them are harmed, and that explanation for gender inequality lies in societal culture and values rather than its structures and institutions. In this vein, socialization into gender roles produce rigid expectations of men and women (Thompson, 2016, para. 4).

The theory is derived from the liberal political philosophy in the enlightenment period which centred on the core ideas of equality, freedom, universal rights and democracy (Tong, 2009). Unlike Radical Feminists therefore, Liberal Feminists do not advocate revolutionary changes in a democratic setting as a solution to the problem of gender discrimination. Instead, they advocate certain changes such as legislations and reforms within the existing political structure in order to foster equal opportunities for males and females in every ramification. The key idea is to bring women full force into the development process - through increased participation and improved share in resource distribution, employment and income - and to bring dramatic improvements in their living conditions (Peet and Hartwick, 2009 p.255).

Viewing the phenomenon of GBV in Nigerian society through the lens of the liberal feminist theory, it can be clearly seen that VAW is high in the country because many cultural values and religious practices directly and indirectly cause it. For Example, in attempts to preserve girls' virginity for their future husbands, many parents subject their female children to some violent and harmful practices such as genital mutilation and child marriage. Girls usually graduate from such abuse in their families of orientation into another cycle of abuse in families of procreation. - The root cause of the phenomenon 
can be understood to be patriarchy. Nigeria is a patriarchal society where males are regarded as the dominant group and females as their subordinate. This value fosters belief in men's entitlement to the services, obedience, loyalty and subservience of women. It is in attempt to exercise their culturally given authority in relationship that men seek to control women through variety of means some of which constitute violence psychologically, physically and otherwise. There is an increasing evidence to suggest that marital violence revolves around cultural definitions of appropriate sex roles and partners' expectations of each other's roles, particularly those related to wife obedience and domestic services. In many occasions, the failure of the women to satisfy their partners' expectations of their roles results in incidents of violence against them. The women's heavy economic dependence on their husbands, encouraged by the cultural expectation of men being the bread-winners of their families has continued to aid the perpetuation of this pattern.

While the feminist theory is criticized on the ground that it exaggerates male power and implies that all men exercise the same degree of authority over women, it still offers the most relevant explanatory and predictive basis in the light of VAW in Nigeria and beyond. As Bailey (2016, p.669) rightly said, the theory has been instrumental in fuelling the significant legal, educational and policy initiatives of women's rights movements which have improved the plight of women in diverse contexts. Also, in a study on assessing the compatibility and applicability of the Liberal Feminist theory in Ethiopian context, Enyew and Mihrete (2018, p.63) asserted that the solutions to gender inequality offered by liberal feminist is gradually reducing stereotypes and prejudices as well as customary and other practices that perpetuate gender discriminations in Ethiopia, and that Ethiopian government is also promoting equality of opportunities between men and women in different aspects such as education, voting and employment.

\section{CONCEPTUAL FRAMEWORK}

Gender Based Violence, Violence against Women, Domestic ViolenceIntimate Partner Violence, Woman and Man, are the terms that form the crux of this analysis. They shall be conceptualized in this section. aGender Based Violence (GBV):

This refers to any socially injurious action, threat of such action or omission against a person on the basis of their gender. Gender is related to but is not the same as sex although the two terms are often used interchangeably. Sex refers to the biological characteristics that make people male and female while gender refers to the socially attributed differences that make them masculine and feminine respectively. Sex is the major determinant of the roles and responsibilities males and females are given in different cultures which in turn give them their respective genders and subject them to different kinds of opportunities and privileges. Once the basis for any form of violent act is the victim's gender, it is GBV irrespective of the victim's and perpetrator's genders. Therefore, both male and female can be victims of GBV.

\section{Violence Against Women (VAW):}

This is a more specific term, referring to any form of GBV that is primarily or exclusively committed against any member of the female sex. In this light, violence against girls, being younger members of the female sex can also be regarded as VAW. This is because feminity is ascribed to a female right from childhood. The basis for VAW is not the concept "gender" but one of its variables "feminine". It is therefore one side of the GBV coin.Domestic Violence (DV):

This term is limited in geographical scope as it refers to any act of violence that occursonly within a family, be it a family of two or an extended family setting. The basis for DV is therefore the social context of its occurrence rather than the characteristic of the victim. It therefore implies that either male or female can be a victim of DV. It usually occurs because the victim occupies some vulnerable position within a family. While it is not always gender based, it often is, and most often than not, females are at the receiving end because they are generally perceived as weak and thus vulnerable. Consequently, a significant percentage of VAW in many societies are DV.

Intimate Partner Violence (IPV):

This term refers to any abusive behaviour in a $\mathrm{man} /$ womanrelationship. Such an abusive behaviour is usually used by one person to gain or maintain power and control over their partner. The basis for such form of violence is the social and emotional attachment of the victim to the abuser. Like GBV and DV therefore, IPV can have either of the sexes as victim. But due to their perceived physical and cultural inferiority, females, especially the married, are the victims in most cases. IPV can also be considered DV if the partners live together as members of a family. Thus, IPV, VAW and DV can form the three sides of a triangle.

Woman:

A woman refers to anadult member of the female sex. The term adult in this context refers to one who is up to the legal age of consent in Nigeria, which is 18. Because the term woman is often used in Nigeria to refer to married females, the prevalence of child marriage in Nigeria makes the dividing line between a girl and a woman arbitrary. In this context therefore, married girls below the age of 18 are referred to as child brides. The discourse on VAW in this paper cannot totally exclude girls since feminity is ascribed to a female right from birth and many women have been exposed to GBV right from childhood. age.

Man: 
A man refers to an adult e member of the male sex. The problem with the application of this definition is that the term is often used in Nigeria to refer to any male who is self-reliant and is deemed capable of shouldering the financial responsibilities of a family of procreation. Some of them may not be up to the age of 18 and are therefore not covered by the foregoing definition. But unlike the concept of woman, the concept of man is hardly affected by child marriage due to the financial burden that makes under-age marriage among males in the country very rare. age. Notwithstanding, males below the age of 18 are not totally excluded from the discourse in this paper since based on Social Learning propositions, most of them have the tendency to perpetrate VAW when they grow up as most perpetrators of the act learnt such behaviours right from childhood.

\section{VIOLENCE AGAINST WOMEN IN NIGERIA}

Nigerian women have over the years suffered political, social and economic discrimination. While they struggle for social, political and economic rights, they experience violence in the form of rape, physical abuse, verbal abuse, incest, Female Genital Mutilation (FGM), denial of food, forced marriage and child marriage among many others. Some cultural and religious values coupled with rapid modernization and westernization have made GBV a regular experience for most women in various communities across the country. The level of VAW in Nigeria is increasing by the day, with a staggering number of women in various communities experiencing violence. According to Women At Risk International Foundation (WARIS, para. 4), in a year, over 30\% of women in the country experience one form of DV or another. Similarly, the 2018 Nigeria Demographic and Health Survey (NDHS) reports that approximately $31 \%$ of women aged between 15 and 49 had experienced some form of physical violence since age 15 and $14 \%$ had experienced physical violence in the 12 months preceding the survey. Also, Muluneh et al. (2020) carried out a systematic review and meta-analysis to quantitatively summarize the prevalence of GBV in Sub Saharan Africa. They sourced data on the prevalence of IPV among women aged 15 - 49 in various Sub Saharan African countries from 25 studies. The findings showed the prevalence ranged from as low as $13.9 \%$ in a study conducted on perinatal women with depression symptoms in South Africa to as high as $97 \%$ in a study conducted among rural women in Nigeria. The review concluded that women living in Eastern and Western African regions (which include Nigeria) experienced the highest levels of GBV over the years.

Furthermore, in a study on torture and the female gender in Nigeria, Ezeilo and Ohia (2006) sampled 2000 respondents, comprising 1052 females and 948 males. Their findings revealed that different forms of torture were used on females in Nigeria which include, beating, withholding of salary, need denial, suppression, sexual harassment, rape, forced widowhood practice, abusive speech, destructions of property, deprivation, threats, and child abuse to name a few. And according to the study, these affect women across all social classes.

However, lower class women especially full-time housewives and those working in the informal sector are more prone to GBV than those belonging to middle and upper classes especially those working in the formal sector (Adebayo, 2003, p.12). In other words, social class and economic dependence on men have significant effect on women's victimisation. As a result of this, many women in the country now seek economic independence through entrepreneurship, skilled and unskilled labour. Domestic violence among other forms of GBV has only become so pervasive in the country that even highly educated and empowered women are not yet totally free from it..

The reasons for wife battery range from silly offences like refusal to respect a husband to more serious ones like having extra marital affairs. Others include refusal to have sex, leaving the house without permission, keeping bad company, drinking alcohol, cooking bad food or cooking late and disrespect shown to in-laws. Adebayo (2003, p. 19) cited poverty, stalking, direct interference in husband's supposed secret affairs, wickedness, lack of trust, uncaring nature, power tussle and impatience as factors leading to wife battery.. It goes without saying that the practice of wife battery is very injurious to the women's health. It is linked with a multitude of adverse physical health outcomes including acute injuries, chronic pain, gastrointestinal illness and substance abuse (Taft and Watson 2008). Others health consequences of the act are , mental instability, gynaecological problems, miscarriage, permanent disabilities, depression and haemorrhage. In fact, it is a significant cause of female morbidity and mortality.

Even widows are not spared as many have, over the years, found themselves at the receiving end of harmful widowhood practices which prevent them from living normal life and even forced some to engage in risky sexual practices to sustain themselves and their children. Widows are often accused of killing their husbands and are consequently either ostracised from the community or subjected to degrading widowhood rites to prove their innocence. The resulting stigma of such rites is often too much for many to bear regardless to whether or not they are immediately proved guilty. While only malicious reasons make some in-laws to dispossess widows of all family belongings and or evict them from their homes, some cultures in the country out rightly exclude women from inheriting their husbands' (or even fathers') properties. The bottom line is,

Land ownership laws as well as prevalent customary practices in some states exclude women from property ownership. Because of this, property is held under the man's name and passed on through a patrilineal lineage within the group. In Southeast Nigeria, a widow's right to own or even use the land is not secured, and relatives commonly seize the property of the widows (World Bank, 2019, p.14). Rape and other 
forms of sexual harassment is another form of VAW that has been flourishing in Nigeria. Many researches have been conducted over the years but the reported incidents of the menace vary depending on study design and methodology (Akinlusi et al., 2014, para.13). The World Health Organization (2011:11) reported that 1 in every 5 women is a victim of sexual assault and 1 in every 10 women is sexually assaulted in Nigeria every day. Sexual assault for most of these women began since they were children, that is, before they attain the legal age of consent which is 18. This is because child sexual abuse is very rampant in the country and in almost all cases the victims are girls. While there is some evidence that sexual violence against boys occurs more often than previously known, it is very difficult to have any reliable data in any setting including in emergencies (Muluneh et al., 2020). The rate of child sexual abuse is estimated to vary between $5 \%$ and $38 \%$ across different parts of the country. Findings from a National Survey carried out in 2014 on Violence Against Children in Nigeria confirmed 1 in 4 females reported experiencing sexual violence in childhood with approximately $70 \%$ reporting more than one incident of sexual violence (WARIF, para. 4). In the same study, it was found that $24.8 \%$ of females' aged 18 to 24 years experienced sexual abuse prior to age 18 of which $5.0 \%$ sought help, with only $3.5 \%$ receiving any services. According to Kawu (2013,para.4), a survey by Positive Action for Treatment Access (PATA ) revealed that over $31.4 \%$ of girls who participated in the survey said their first sexual encounter had been rape or forced sex of some kind. In its own study, the United Nations International Children Education Fund (UNICEF, 2015) reported that 1 in 4 girls in Nigeria had experienced sexual violence before the age of 18 . The true magnitude of child sexual abuse simply remains difficult to determine. However, what is obvious is that it affects significantly more girls than boys, it usually occurs in settings the child is familiar with, most abusers are known to the children before the onset of the abuse, and fewer than 5 out of every 100 of the children who reported violence received any form of support (Ng'ondi, 2015, p. 16).

According to David et al., (2018, p. 200), the sheer difficulty in determining the true magnitude of child sexual is a result of the culture of silence around the issue of child sexual abuse, non-disclosure of abuse by the victims arising from fear of further harm from the perpetrator or of being blamed, fear of social stigmatization by members of the public, cultural inhibitions and the tendency for ineffectual prosecution of the offenders. Poverty, ignorance, poor education, and unstable home environments are some of the social factors associated with the phenomenon.

Victims of sexual assaults, like those of wife battery, experience significant health, social and economic consequences which may be immediate or delayed. It is noteworthy that the violence involved in an attempted sexual assault can have the same impact on the victim as a completed one (Akinlusi etal., 2014, para14). The health consequences of sexual assault include sexually transmitted diseases, unwanted pregnancies, unsafe abortions, physical injuries, immediate psychological reactions such as shock, shame, guilt and anger; and long-term psychological outcomes like depression, posttraumatic stress disorder, suicidal ideation, lack of sexual enjoyment, and fear(Akinlusi et al., 2014, para 14).

Furthermore, a review on violence against women by WHO (2013) showed that women who have been sexually assaulted by non-partners are 2.3 times more likely to use alcohol and 2.6 times more likely to experience depression or anxiety, while those abused by partners are 1.5 times more likely to have sexually transmitted diseases including HIV. This is because most of them hardly disclose their predicament to anyone to seek help due to fear or the fear of stigmatisation. Of course, Nigeria has one of the lowest rates of help-seeking behaviour in the world with north east geopolitical zone where only $23 \%$ of female survivors of IPV were reported to have sought help - having the lowest rate in the country (World Bank, 2019, p.13). It is further reported by the World Bank (2019) that among women aged 15-49 who have survived physical or sexual violence, whether the perpetrator was an intimate partner or not, $45 \%$ never sought help or told anyone, only $31 \%$ sought help from any source, and $12 \%$ told someone about their experience but did not seek help.

Forced marriage and child marriage are closely linked and are prevalent in Nigeria mostly with females in the wrong side of the union. According to UNICEF (2016), 43\% of girls in Nigeria are married before the age of 18 . In fact, Nigeria has the largest number of child brides in Africa with more than 23 million girls and women who were married as children, most of them from poor and rural communities (UNICEF, 2018). A girl from poor family is often seen by her parents as a commodity that can upturn the fortunes of the whole family through marriage to a wealthy person. Once a suitor is found for the girl, her age or consent matter little to the parents. Unlike sexual assault and wife battery, forced and child marriage are not perceived as deviant acts in most communities in Nigeria. In fact, they are directly encouraged by cultural and religious values.

Islamic religion in particular reinforced the traditional value of having to marry off girls as virgins with early marriage perceived as the only way to ensure that. This is why the phenomenon is more prevalent in rural areas where the influence of tradition is still strong and in the northern part of the country where Islamic religion is dominant. 2). Data from Multiple Indicator Cluster Survey showed that among the 36 states of Nigeria and the FCT, the states with the highest proportion of girls married by age 15 and 18 are the north western states of Zamfara (48.6\%) and Jigawa (87.4\%) respectively (UNICEF 2018). While data suggests a decline of $9 \%$ in the prevalence of the act since 2003 with a projected further decrease of $6 \%$ by 2030 , Nigeria's rapid population growth means the actual number of child brides in the country will in fact increase by more than one million by 2030 and double by 2050 (UNICEF, 2018 para.2). 
Female Genital Mutilation (FGM) is another violent cultural practice which many women in Nigeria are now facing its negative consequences having being subjected to it as children. Over 1 in 4 Nigerian women (27\%) aged 15-49 have undergone FGM, with the absolute number being about 20 million, a figure that makes the country the third with the highest absolute number of FGM victims worldwide (UNICEF, 2018, para.3). The practice existed in many societies across the world for various reasons but has now greatly declined. It has even totally disappeared in many societies due to its obvious health consequences and enlightenment. Unfortunately, there are many communities in Nigeria that still justify its continuation on grounds of perceived moral obligation or desire to preserve girls' virginity for family honour.

However, the prevalence of FGM in the country is dropping as a result of massive enlightenment campaigns against the act by various civil society organisations. While it is projected that the percentage of the victims (being $27 \%$ in 2018) will further decline by the year 2030, population explosion in the country is expected to result in the actual numbers of those affected (being 20 million in 2018) to remain unchanged (UNICEF, 2018, para.3).The health consequences of FGM are numerous. It often damages the women's sexuality and increases the HIV transmission risk faced by women as unsterilized instruments are often used in the cutting process (Brady, 1999: p. 711). It also leads to injuries to the perineum or rectum, haemorrhage, ulceration, infection and retention of urine. The long-term health consequences of the act includes chronic pelvic infections, coital difficulties, lack of orgasm, obstetric complications, permanent frigidity, temporary trauma and psychosis (Akinola, 2000, p. 14).

Generally, harmful practices deeply rooted in culture and traditions such as forced and child marriage, FGM, and forced widowhood practices among others are more prevalent in rural than urban areas as discussed above. Notwithstanding the strong influence of culture and religion in the differential rate, lower level of education in rural areas also influence the course. For example, in a study on violence against women in relation to literacy and area of residence in Ethiopia, Deyessa et al. (2010) found higher rate of IPV in rural areas than urban areas regardless of the victims' educational attainment, but according to the findings, it was higher among rural women who were married to less educated husbands.

Similarly, in a meta-analysis on the effect of rural-urban residence and education on IPV, Nagabbala et al. (2021) analysed IPV data on 233,585 women aged 15-49 years from 44 demographic and health surveys conducted between 2000 and 2018 in 29 Sub Saharan African countries. Their findings revealed that women living in rural areas were more likely to have experienced higher rates of IPV compared to women living in urban areas. They further revealed that the prevalence of any form of IPV was generally higher among women living in rural areas (60\% of the surveys) and the less- educated women (73\% of the surveys) with the most common forms of IPV reported being physical (31.5\%), emotional (27.4\%) and sexual (12.9\%).

Finally, it is important to mention that although women are the primary victims of GBV, its overall social and economic costs negatively affects the developmental trajectory of the the entire country. The economic costs of GBV include expenditures on service provision, foregone income for women and their families, decreased productivity, and negative impacts on human capital formation, which are burdensome to developing economies (World Bank, 2019). Therefore, being key actors in the developmental process, the freedom of Nigerian women is directly linked to the country's development.

As Terjesen (2004) said in his review of Amartya Sen's Development As Freedom, development hinges on women's earning power, economic role outside the family, literacy, education and property rights. In the light of the Nigeria's social objectives built on the ideals of freedom, equality and justice, development will entail social transformation that fosters widespread freedom from all forms of discrimination and changes the society in favour of marginalised groups. But even in economic sense, development in Nigeria will mean not only growth in the country's GDP but also economic transformation that results in income redistribution, better living standards for the poor, equal access to medical care and widespread freedom (Peet and Hartwick, 2009 p.196).

\section{The Legal Framework on Violence Against Women in Nigeria}

The bedrocks upon which Nigerian legal system is built are the ideals of freedom, equality and justice being part of the country's social objectives enshrined in the 1999 constitution of the Federal Republic of Nigeria. In the constitution, there are numerous provisions offering protection to all citizens against violence, injustice and discrimination. For example, section 33 (1) of the constitution states that every person has a right to life and no one should be unjustly deprived of his life. Section 34 provides for the dignity of a person and prohibits torture or any degrading treatment of a human being. Section 36 (5) provides that in determining any civil and criminal matter, the accused person should be given fair hearing as every accused person is innocent until the contrary is sufficiently proved in a competent court of jurisdiction. There is also the Child Rights Act of 2003 which provides for detailed protection of a girl child until she attains the legal age of 18. The Act seeks to end forced labour and child marriages, and to ensure effective health services for pregnant teenage girls in the country.

In addition to the foregoing, the federal government of Nigeria has ratified many international and regional conventions that condemn GBV and other acts that temper with the fundamental rights of women and other vulnerable groups. Some of them are summarised in table 1 below. 
Table 1.International/Regional Agreements on GBV and Sexual Exploitation and Abuse Adopted by Nigerian Government

\begin{tabular}{|c|c|c|c|}
\hline Title & Year Adopted & Description & Year Ratified \\
\hline $\begin{array}{l}\text { Convention on the Elimination of } \\
\text { All Forms of Discrimination } \\
\text { Against Women (CEDAW) }\end{array}$ & 1979 & $\begin{array}{l}\text { Adopted in } 1979 \text {, but the general recommendation } 19 \text { on } \\
\text { violence against women was not adopted by the CEDAW } \\
\text { committee until 1992. It recognizes GBV as a form of } \\
\text { discrimination and recommends that states take measures to } \\
\text { prevent and respond to violence against women. } \\
\text { Article } 6 \text { calls for states to "suppress all forms of trafficking } \\
\text { and exploitation of prostitution of women." }\end{array}$ & 1985 \\
\hline $\begin{array}{l}\text { African Charter on Human and } \\
\text { Peoples' Rights }\end{array}$ & 1981 & $\begin{array}{l}\text { Calls for the elimination of discrimination against women } \\
\text { and the protection of the rights of women and children. } \\
\text { Prohibits all forms of exploitation, particularly slavery. }\end{array}$ & 1983 \\
\hline $\begin{array}{c}\text { Convention on the Rights of the } \\
\text { Child }\end{array}$ & 1989 & $\begin{array}{c}\text { Defines a child as a person under the age of } 18 . \\
\text { Commits state parties to protecting children from all forms } \\
\text { of mental and physical violence, as well as sexual } \\
\text { exploitation, child marriage, abuse, harmful traditional } \\
\text { practices, and prostitution. }\end{array}$ & 1991 \\
\hline $\begin{array}{l}\text { African Union Charter on the } \\
\text { Rights and Welfare of the Child }\end{array}$ & 1990 & $\begin{array}{l}\text { Defines a child as a person under the age of } 18 \text {. } \\
\text { Commits states to protecting children from physical and } \\
\text { sexual abuse. }\end{array}$ & 2000 . \\
\hline $\begin{array}{c}\text { Rome Statute of the International } \\
\text { Criminal Court }\end{array}$ & 1998 & $\begin{array}{c}\text { Recognizes a spectrum of GBV as war crimes and crimes } \\
\text { against humanity, including rape, sexual slavery, forced } \\
\text { prostitution, and forced sterilization. }\end{array}$ & 2001 \\
\hline $\begin{array}{l}\text { Protocol to Prevent, Suppress and } \\
\text { Punish Trafficking in Persons, } \\
\text { Especially Women and Children, } \\
\text { supplementing the United Nations } \\
\text { Convention Against Transnational } \\
\text { Organized Crime. } \\
\end{array}$ & 2000 & $\begin{array}{l}\text { Calls on states to criminalize and take steps to prevent } \\
\text { trafficking. } \\
\text { Commits states to providing physical, psychosocial, and } \\
\text { social support to trafficking victims. }\end{array}$ & 2001. \\
\hline $\begin{array}{l}\text { Protocol to the African Charter on } \\
\text { Human and Peoples' Rights on the } \\
\text { Rights of Women in Africa } \\
\text { (Maputo Protocol) }\end{array}$ & 2003 & $\begin{array}{l}\text { - Calls on states to protect rights of women and girls, such } \\
\text { as property rights, rights to a consensual marriage, } \\
\text { protection against child marriage, widows' rights, } \\
\text { inheritance rights, and protection against all forms of } \\
\text { violence. }\end{array}$ & 2004 \\
\hline
\end{tabular}

Source: Adapted from the World Bank (2018).

These seem to imply that the Nigerian government has been committed to the fight against GBV for years. But while the successive governments did not hesitate to ratify the aforementioned agreements, the Nigerian constitution requires their domestication through adoption by the National and State legislatures and none has been yet. Also, there has not been national law expressly protecting the rights of women against violence before the year 2015 despite the perpetual violation of the fundamental rights of women in the country and the calls for such a law. Where there was a semblance of protection to women in the existing national laws, there were often inadequacies and limitations by virtue of the undue burden placed on the victims. For this lack of effectiveness in the criminal justice system with regards to the fight against GBV as well as severe pressure from Civil Society actors the Violence against Person Prohibition(VAPP) Bill which was presented to the National Assembly since 2004 was finally signed into law on $23^{\text {rd }}$ May, 2015.

The VAPP Act is now the only law in place that transcends the country's Criminal and Penal Code in guaranteeing justice and protecting the rights and properties of victims of sexual and GBV across the country. Section 45 of the Act makes consequential amendments to the Criminal Code, Penal Code and Criminal Procedure Code to the effect that any provision of the Act shall supersede any other provision on similar offences in the Criminal Code, Penal Code and Criminal Procedure Code (NAPTIP, 2018, para.8).In section 38 of the Act, it is provided that in addition to the rights guaranteed under Chapter IV of the 1999 Constitution as amended; victims of violence have the right to receive physical, medical, psychological and legal assistance through governmental and non-governmental agencies providing such assistance. Thus, the major objectives of the VAPP Act are to eliminate violence in private and public life, to provide maximum protection or effective remedies for victims and to accordingly punish offenders. The VAPP Act simply paves way for justice by guaranteeing freedom and respect to human rights as a wide range of GBV including wife battery, harmful widowhood practices, genital mutilation and rape are all recognized as punishable offences in the Act (Durojaiye, 2020, para.11). A summary of some of the offences defined in the Act and their respective penalties is provided in Table 2 below. 
Table 2.Offences And Penalties in VAPP ACT

\begin{tabular}{|c|c|c|}
\hline & Offence & Penalty \\
\hline 1 & $\begin{array}{c}\text { Performance of Female Circumcision/Genital } \\
\text { Mutilation }\end{array}$ & $\begin{array}{c}\text { A term of imprisonment not exceeding 4 years or a } \\
\text { fine not exceeding N200,000.00 or both }\end{array}$ \\
\hline 2 & Forceful Ejection from Home & $\begin{array}{c}\text { Imprisonment not exceeding } 2 \text { years or to a fine not } \\
\text { exceeding N300,000.00 or both }\end{array}$ \\
\hline 3 & $\begin{array}{c}\text { Damage to Property with Intent to Cause } \\
\text { Distress }\end{array}$ & $\begin{array}{c}2 \text { years Imprisonment or to a fine not exceeding } \\
\text { N300,000.00 or both. }\end{array}$ \\
\hline 4 & $\begin{array}{c}\text { Forced Financial Dependence or Economic } \\
\text { Abuse }\end{array}$ & $\begin{array}{c}\text { Imprisonment not exceeding 2 years or to a fine not } \\
\text { exceeding N500,000.00 or both }\end{array}$ \\
\hline 5 & $\begin{array}{c}\text { Forced Isolation or Separation from Family and } \\
\text { Friends }\end{array}$ & $\begin{array}{c}\text { Imprisonment not exceeding 6 months or a fine not } \\
\text { exceeding N100,000.00 or both }\end{array}$ \\
\hline 6 & Emotional, Verbal and Psychological Abuse & $\begin{array}{c}\text { Imprisonment not exceeding } 1 \text { year or to a fine not } \\
\text { exceeding N200,000.00 or both }\end{array}$ \\
\hline 7 & Harmful Widowhood Practices & $\begin{array}{c}\text { Imprisonment not exceeding } 2 \text { years or a fine not } \\
\text { exceeding N500,000.00 or both }\end{array}$ \\
\hline 8 & $\begin{array}{c}\text { Abandonment of Spouse, Children or Other } \\
\text { Dependants Without Sustenance }\end{array}$ & $\begin{array}{c}\text { Imprisonment not exceeding } 3 \text { years or a fine not } \\
\text { exceeding N500,000.00 or both }\end{array}$ \\
\hline 9 & Intimidation & $\begin{array}{c}\text { Imprisonment not exceeding 1 year or a fine not } \\
\text { exceeding N200,000.00 or both }\end{array}$ \\
\hline 10 & Spousal Battery & $\begin{array}{c}\text { Imprisonment not exceeding } 3 \text { years or a fine not } \\
\text { exceeding N200,000.00 or both }\end{array}$ \\
\hline
\end{tabular}

Source: Based on data from the VAPP ACT (2015).

However, notwithstanding the comprehensiveness of the VAPP, it is yet to yield a reduction in violence towards women and enactment. One of the main challenges of implementing it is that DV in particular is grossly underreported as the police often dismiss it as a family matter (Itoro, 2005, p.83). Other reasons for the under reporting of DV in Nigeria include the stigma around it, the idea that a woman is partially responsible for being victimized (under the assumption that she must have transgressed in some way from her socially expected role and therefore deserves punishment), fear of family disgrace if the issue is not addressed privately, and a dearth of and lack of awareness of specialized GBV services (World Bank, 2019). In the same vein, rape and other forms of sexual assaults are seriously under-reported due to the fear of the social stigma on the victim of the abuse. In some cases, the victims of the abuse are even blamed for their seductive postures or dressing.

In instances where the victims reported to the police, the police were often reluctant to carry out proper investigation and prosecution and eventually dismiss the case for lack of evidence. In a fact-checking review of law reports and news reports that centred on court cases involving rape charges, only 65 rape convictions were gathered between 1973 and 2019 (Adebajo, 2019, para. 10). Shortage of women judges and lawyers is partly responsible for this. In a study on Gender and Corruption, Maureen \& Timothy (2014) rightly recommended that women judges should be appointed in Nigerian courts because a policy of appointing more women judges will help improve gender balance in the legal realm and access to justice throughout the nation. Another problem of the VAPP Act is limitation in its geographical scope. While Nigeria is a federation consisting of 36 states and the Federal Capital Territory (FCT), section 47 of the VAPP Act stipulates that the Act applies only in the FCT.. And in spite of the agitations and clamours from civil society organisations across the country, so far fewer than 20 among the 36 states of the federation have domesticated the Act. Northern states are more wanting in this regards than their southern counterparts. While domesticating the VAPP Act in all the states of the federation will go a long way in aiding the fight against GBV throughout the country, there is need for different public policy response to the problem in the two regions (north and south) since the rates of the causative factors of the phenomenon like poverty, unemployment, ignorance and cultural practices differ across the geographical areas.

\section{V.CONCLUSION}

It is clear in the light of the foregoing analysis that VAW is rampant in Nigeria and remains a stumbling block to the achievement of Nigeria's national objective of ensuring equality of opportunities for all citizens, freedom from all forms of discrimination and justice to all and sundry The phenomenon is widespread in not just rural but also urban areas with millions of women in the country suffering from wife battery, harmful widowhood practices, sexual assaults, forced marriage and FGM among other forms of GBV all of which lead to a multitude of adverse physical, economic and social consequences that affect not just the women but the country at large. General causative factors of the phenomenon are cultural and religious values as well as early exposure to violence.

While there is concerted effort at the global level to eliminate GBV, not much has been forthcoming at the local level as successive governments in the country have demonstrated little or no will to enforce all international conventions and protocols on the issue. The enactment of the VAPP Act in 2015 is a giant stride in this regards but the limitations of its geographical scope, the reluctance of many states to domesticate it as well as the ineffectiveness of the Nigerian 
criminal justice system continue to militate against its efficacy.

In the light of the fight against GBV, Nigeria's Police Force and other law enforcement agencies as well as the courts are in dire need of overhaul. Bribery and corruption, being a long standing issue affecting the Nigerian police, judiciary and other law enforcement agencies should be eliminated or at least drastically reduced by improving the conditions of service of their respective personnel. The problem of shortage of manpower affecting the agencies should be addressed through massive recruitment, and women should be given special consideration in the recruitment process in order to improve gender balance in all the agencies and access to justice for women through each of them. The personnel across all the agencies should as well be equipped with modern gadgets and should be well trained in line with global best practices of maintaining law and order hinged on the ideals of equality before the law, freedom and justice. Only in doing so will efficiency in the process of arresting, prosecuting and convicting the perpetrators of violence against women among other crimes be ensured. Doing so will also ensure that the convicted culprits of GBV are not hardened but rehabilitated. be......... .

Also, more women economic empowerment programmes need to be initiated and adequately funded since there is a positive correlation between women's heavy economic dependence on men and GBV on one hand and between women economic freedom and the country's development on the other hand. The involvement of not only the government but also members of the public, civil society and nongovernmental organizations is critical to achieving the objectives of such programmes while fighting violence against women in the county. It is in this vein that UNICEF's child protection programme works with key ministries and partners across multiple levels and sectors to generate and analyze evidence for legal reform and increased public financing for children. The program aims to design quality age and genderspecific services to provide preventive and response interventions for children who are victims of, or at risk of violence, abuse, neglect and exploitation through strengthened child protection systems (UNICEF, 2018, para. 4). More of such programmes are needed too because in the light of Social Learning theory, it is clear that eliminating violence against children will upset the trend of the rising incidents of VAW in the country as male children who did not witness violence are less likely to perpetrate violence when they grow up.

Both governmental and non-governmental organizations need to intensify efforts and work hand in hand to organize workshops and seminars in both urban and rural areas, and also widen their sensitization campaigns against GBV in the 36 states of the federation and the FCT. There is also need for more studies by academics and other relevant stakeholders on the various dimensions and nature of GBV.. These will enlighten the general public on their obligations in the fight against GBV and propel the government to act drastically and urgently towards stemming the tide and paving the way for meaningful socio-economic development in the country.

\section{REFERENCES}

[1] Adebajo, K. (2019, July 3). Fact check: No, it is not true Nigeria has recorded only 18 convictions in rape cases. International Center for Investigativer Reporting. https://www.icirnigeria.org/fact-check-no-it-isnt-true-nigeria-hasrecorded-only-18-convictions-in-rape-cases/

[2] Adebayo, A. (2003). Family violence against women: A comparative study of families in formal and informal business sectors in Ibadan metropolis. Nigeria Institute of Social Economic Research.

[3] Ahmad, F., Riaz, S., Barata, P., Stewart, D. (2004). Patriarchal beliefs and perceptions of abuse among South Asian immigrant women. Violence Against Women, 10(3): 262-282.Akinola, J. (2000, February 1). Women, discrimination and harmful traditional practices.

Daily Times.

[4] Akinlusi F. M., Rabiu, K. A., Olawepo, T. A., Adewunmi, A. A., Ottun, T. A., Akinola, O. I. (2014) Sexual assault in Lagos, Nigeria: a five year retrospective review. BMC Women's Health 14, 115. http://bmcwomenshealth.biomedcentral.com/articles

[5] Anderson. J. F. and Kras's (2005). Revisiting Albert Bandura's social learning theory to better understand and assist victims of intimate personal violence. Women \& Criminal Justice: 17 (1).

[6] Bachman, R. (1994). Violence against women: A National crime victimization survey report. Bureau of Justice Statistics, U.S. Department of Justice.Bandura, A. (1977). Social learning theory. General Learning Press.

[7] Bandura, A. (1986). Social learning theory (2 ${ }^{\text {nd }}$ Ed.). PrenticeHall.

[8] Bailey, E. L. (2016). Feminism, liberal. The Wiley Blackwell Encyclopedia of Gender and Sexuality Studies, I. 669-671.

[9] Berkley, S., Bobadilla, J., Hecht, R., Hill, K., Jamison, D. T., Murray, J. L., Musgrove, P., Saxenian, H., Tan, J.(1993). World development report 1993: Investing in health (English). World Bank

Group.http://documents.worldbank.org/curated/en/468831468340 807129/World-development-report-1993-investing-in-health

[10] Brady, M. (1999). Female genital mutilation: compilations and risk of HIV transmission. AIDS patient care and STDs. 13, (12):709-716.

[11] Daru P. H., Osagie E. O., Pam. I. C., Mutihir, J. T., Silas, O. A., Ekwempu, C. C. (2011). Analysis of cases of rape as seen at the Jos University Teaching Hospital, Jos, north central Nigeria. Nigerian Journal of Clinical Practitioners.14 (1): 47-51. https://doi.org/10.4103/1119-3077.79240.

[12] David, N., Ezechi, O., Wapmuk, A., Gbajabiamila,T., Ohihoin, A., Herbertson, E.,Odeyemi, K. (2018). Child sexual abuse and disclosure in South Western Nigeria: a community based study. African Health Sciences.2018 Jun; 18(2): 199-208. https://doi.org/10.4314/ahs.v18i2.2

[13] Delaney, A. X. (2015). Violent socialization and youth violence across different nations: international variations in familial and contextual factors. in violence and crime in the family: patterns, causes, and consequences. Emerald Group Publishing Limited.

[14] Deyessa, N., Berhane, Y., Ellsberg, M., Emmelin, M., Kullgren, G., Högberg, U. (2010). Violence against women in relation to literacy and area of residence in Ethiopia. Glob Health Action. 3 (1): 2070.

[15] Durojaiye, S. (2020, June 12). Hall of shame: 23 states yet to pass anti- rape law, majority are from the North. International Center for Investigative Reporting. https://www.icirnigeria.org/hall-ofshame-23-states-yet-to-pass-anti-rape-law-majority-are-from-thenorth/

[16] Enyew, B. E., Mihrete, A. G. (208). Liberal feminism: assessing its compatibility and applicability in Ethiopian context. International Journal of Sociology and Anthropology 10, (6): 5964. https://doi:10.5897/IJSA2018.0769 
[17] Erikson, L., \& Mazerolle, P. (2015). A cycle of violence? Examining family-of-origin violence, attitudes, and intimate partner violence perpetration. Journal of Interpersonal Violence, 30 (6): 945-964.

[18] European Union (n. d.). What is gender-based violence? https://ec.europa.eu/info/policies/justice-and-fundamentalrights/gender-equality/gender-based-violence/what-gender-basedviolence_en

[19] Ezeilo, J., Ohia, N., (2006). Torture and the female gender : report of a National Survey on Torture in Nigeria. Women's Aid Collective.

[20] Fitaw, Y., Haddis, K., Million, F. G., Selassie, K. (2005). Gender based violence among high school students in North West Ethiopia. Ethiopian Medical Journal. 43 (4): 215-221.Gage, A. J. (2016). Exposure to spousal violence in the family, attitudes and dating violence perpetration among high school students in Portau-Prince. Journal of Interpersonal Violence, 31 (14): 2445-2474. https://doi.org/10.1177/0886260515576971

[21] Garcia-Moreno C., Watts, C. (2011). Violence against women: an urgent public health priority. Bull World Health Organisation. 210.2471/BLT.10.085217.

[22] Itoro, P. (2005).Criminal and civil liability in husband-wife assaults. London: Pentice Hall. Jewkes, R. Abrahams, N. (2002). The epidemiology of rape and sexual coercion in South Africa: An overview. Social Science Medical.55 (7): 1231-1244. https://doi.org/10.1016/S0277-9536(01)00242-8.

[23] Kawu, I. M., (2013, May 23). Nigeria's troubling epidemic of rapes.Vanguard.http://www.vanguardngr.com/2013/05/nigeriastroubling-epidemic-of-rapes/

[24] Maureen, N. U., Timothy, Y. S. (2014). Gender and corruption in Nigeria: causes, nature and effects. African Journal of Modern Society, 3 (3): 177-200.

[25] Muluneh, M. D., Stulz, V., Francis, L., Agho, K. (2020). Gender based violence against women in sub-saharan africa: a systematic review and meta-analysis of cross-sectional studies. International Journal of Environmental Research and Public Health, 17, 903. https://doi:10.3390/ijerph17030903

[26] Nagabbala, M. S., Reddy, T., Manda, S. (2021). Effects of ruralurban residence and education on intimate partner violence among women in Sub-Saharan Africa: a meta-analysis of health survey data. BMC Women's Health. 21:149. https://doi.org/10.1186/s12905- 021-01286-5.

[27] Ng'ondi, N. B. (2015). Child protection in Tanzania: A dream or nightmare. Children and youth services review. 55: 10-17

[28] Nigeria: Violence Against Persons (Prohibition) Act (2015, May 25). https://www.refworld.org/docid/556d5eb14.html

[29] National Agency for the Prohibition of Trafficking in Persons and other related Matters (2018, Sep. 6).VAPP Act. https://www.naptip.gov.ng/vapp-act/

[30] National Population Commission (NPC) of Nigeria and ICF International (ICF) (2019). Nigeria Demographic and Health Survey 2018.

[31] Osuna-Rodríguez M., Rodríguez-Osuna, L.M., Dios, I., Amor, M. I. (2020). Perception of gender based violence and sexual harassment in university students: analysis of the information sources and risk within a relationship. International Journal of Environmental Research and Public Health, 17, 3754. https://doi.org/10.3390/ijerph17113754

[32] Peet, R.,Hartwick, E. (2009). Theories of development: contentions, arguments, alternatives. The Guildford Press.

[33] Perrin, N., Marsh, M., Clough, A., Desgroppes, A., Phanuel C. Y., Abdi, A., Kaburu, F., Heitmann, S., Yamashina M., Ross, B., Read-Hamilton, S., Turner, R., Heise1, L., Glass, N. (2019). Social norms and beliefs about gender based violence scale: a measure for use with gender based violence prevention programs in low-resource and humanitarian settings. Conflict and Health. 13:6. https://doi.org/10.1186/s13031-019-0189-x

[34] Taft, A. J., Watson, L. F. (2008). Depression and termination of pregnancy (Induced Abortion) in a national cohort of young Australian women: the confounding effect of women's experience of violence. BMC Public Health 8: 75.
[35] Terjesen, S. (2004). Amartya Sen's 'development as freedom'. Graduate Journal of Social Science, 1 (2): 344-347.

[36] Thompson, K. (2006, July 6). Liberal, marxist and radical feminist perspectives on society: an introduction. Revise Sociology. https://revisesociology.com/2016/07/11/liberal-radical-marxistfeminist-perspectives-society-sociology/

[37] Tong R (2009). Feminist thought: a more comprehensive introduction. West view Press, University of North Carolina, Charlotte.

[38] UNICEF Nigeria (2015, 10 September). Release of the findings of the Nigeria violence against children survey. http://www.unicef.org/nigeria/media_9588.html

[39] UNICEF Nigeria (2018, Aug. 16). Child Protection. https://www.unicef.org/nigeria/child-protection.

[40] UNICEF (2018). Multiple indicator cluster survey 2016-2017. National Bureau of Statistics, United Nations Children's Fund.

[41] UNFPA. 2013. The state of the world population 2013 motherhood in childhood: facing the challenge of adolescent pregnancy. New York: United Nations Population Fund. https://www.unfpa. $\quad$ org/sites/default/files/pub-pdf/ENSWOP2013.pdf.

[42] UNFPA. Managing Gender-based violence programmes in emergencies: E-learning companion guide. Available at file:///C:/Users/Dreams\%20Reality/Downloads/GBV\%20ELearning\%20Companion\%20Guide_ENGLISH.pdf.

[43] World Bank (2018). Nigeria GBV risk portfolio report. Washington, DC.

[44] World Bank (2019). Gender Based Violence: An Analysis of the implications for the Nigeria for women Project. Washington D C.

[45] World Health Organization (2013, Oct. 20). Global and regional estimates of violence against women. https://www.who.int/publications/i/item/9789241564625 Women at Risk International Foundation (n.d.). Rape Stats in Nigeria. https://warifng.org/rape-stats-in-nigeria/ 